\title{
Olympic Games in COVID-19 times: lessons learned with special focus on the upcoming FIFA World Cup Qatar 2022
}

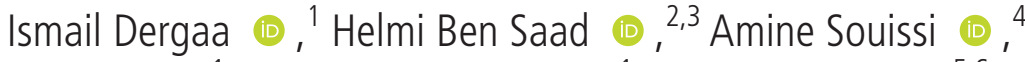 \\ Sarah Musa, ${ }^{1}$ Mariam Ali Abdulmalik, ${ }^{1}$ Karim Chamari ${ }^{5,6}$
}

The COVID-19 pandemic has impacted the global international sports calendar, causing the first-ever postponement of the 2020 Tokyo Summer Olympic Games (OG) and Paralympic Games (PG) until 2021. ${ }^{1}$ Several scientists and sports organisations were strongly opposed to the organisation of these OG and PG. ${ }^{23}$ Variable vaccination rates, waning immunity and the emergence of more transmissible and potentially lethal COVID-19 strains have created additional challenges to hosting large-scale international sporting events. ${ }^{4}$

Contrary to the 2020 Tokyo Games, which were held without fans, another mega event, the FIFA World Cup 2022, will be held in Qatar (21 November-18 December) with over 1.7 million expected visitors (fans, staff, players and media). ${ }^{5}$

\section{FIFA WORLD CUP 2022 CHALLENGES}

We believe the organisation and public health prevention policies adopted during the Tokyo OG/PG were appropriate, with some understandable gaps and lessons learnt related to big events to be revised and optimised. Comparisons between public health policies implemented in Japan and those contemplated for the FIFA World Cup 2022 in Qatar are summarised in table 1 . In contrast to the fan-free Japan OG, which hosted around 118000 visitors over 29 days (ie, around $0.5 \%$ of

\footnotetext{
Primary Health Care Corporation (PHCC), Doha, Qatar ${ }^{2}$ Farhat HACHED Hospital, University of Sousse, Faculty of Medicine of Sousse, Sousse, Tunisia

${ }^{3}$ Laboratoire de Recherche (LR12SP09) 'Insuffisance Cardiaque', Université de Sousse Faculté de Médecine de Sousse, Sousse, Tunisia

${ }^{4}$ Physical activity, Sport, and health, UR18JS01, National Observatory of Sports, Tunis, Tunisia

${ }^{5}$ Aspetar, Orthopaedic and Sports Medicine Hospital, FIFA Medical Centre of Excellence, Doha, Qatar ${ }^{6}$ ISSEP Ksar-Saïd, Manouba University, Mannouba, Tunisia
}

Correspondence to Dr Ismail Dergaa, Primary Health Care Corporation, Doha, Qatar; phd.dergaa@gmail.com the country's population), in the FIFA World Cup 2022, Qatar is expected to welcome foreign fans equivalent to more than half of the country's total population. $^{5}$

Rigorous infection control policies to limit transmission of COVID-19 at the FIFA World Cup 2022 is a priority currently under development by public health experts with a review of past experiences in Qatar. More than a year has passed since the Amir Cup (December 2020) in Qatar with around $20000 \mathrm{spec}$ tators attending. ${ }^{6}$ Qatar also successfully held 77 matches throughout the Asian Football Cup in December 2020 with a smaller number of fans. This was done within a tight bubble system for players and their respective delegations that set a standard for the safe restoration of professional football globally. ${ }^{1} 67$ Undoubtedly, accommodating a tournament with such a huge number of fans like the FIFA World Cup 2022 will necessitate more robust security measures to protect players, spectators and residents. ${ }^{67}$

\section{NEW VARIANTS OF CONCERN}

In November 2021, the WHO reported 'Omicron" (ie, variant B.1.1.529) as a new strain to the COVID-19. ${ }^{8}$ Omicron has the capability to increase transmissibility, grant resistance to treatments and partially evade infection or vaccineinduced immunity. ${ }^{1}$ Further gene mutations associated with the emergence of new variants are expected to affect virus characteristics and capabilities such as transmissibility, sickness severity and immune evasion, creating major uncertainty about the pandemic. ${ }^{1}$ Using the Omicron strain as an example, the virus evolved in such a way that it became more contagious and less severe than previous versions. ${ }^{8}$ In this context, the greater the number of people infected with a virus, the more likely it will mutate into new strains. Omicron, as well as the other COVID-19 variants, could mutate into a more dangerous, severe form, resulting in increased fatalities, imposing a significant case load on the world and decreasing the likelihood of the FIFA World Cup 2022 being successfully hosted. On the other hand, Omicron/other variants could evolve into a less severe form, allowing the FIFA World Cup 2022 to be safely held and filled with spectators.

\section{RECOMMENDATIONS FOR FIFA WORLD CUP 2022}

Given the experience gained from the Tokyo OC/PG, we suggest additional preventative measures be considered, including (1) a mandatory vaccination certificate showing second dose or booster dose within 6 months (number of doses depending on the vaccine durability effectiveness) and/or a recent COVID-19 infection certificate (within the last 6 months: protective adaptive immunity following natural infection of SARS-CoV-2 may persist for at least 6-8 months $)^{9}$; (2) a mandatory COVID-19 immunoglobulin $\mathrm{G}$ antibody titre greater than $33.8 \mathrm{BAU} / \mathrm{mL}$ (which is suggestive of protective immunity against COVID-19) before boarding to Qatar ${ }^{10}$; (3) a COVID-19 passport for athletes, delegates and spectators that includes information about previous exposure to the virus, testing, results, and vaccination status ${ }^{1}$; and (4) providing free COVID-19 rapid test centres for spectators around each stadium and directly pairing these results in the spectator COVID-19 passport and geolocalisation application prior to entering the premises.

Given the scarce evidence regarding the long-term persistence of immunity in either vaccinated or previously infected individuals, the aforementioned measures should provide further protective approaches in reducing the rate of COVID-19 infection during mass gathering. From now until the FIFA World Cup 2022, predictions remain uncertain in terms of the emergence of new variants rendering vaccines infective. However, the rapid spread of the less severe Omicron variant across the globe is bringing hope toward herd immunity. Taken together, we remain optimistic that the FIFA World Cup 2022 will be held safely and with full spectator attendance to witness the 'beautiful game'. 
Table 1 Comparisons between public health policies implemented in Japan (OG and PG 2020, held in 2021) and expected public health policies in FIFA WC Qatar 2022

\begin{tabular}{|c|c|c|}
\hline Key parameters & Japan OG/PG 2020 & FIFA WC Qatar 2022 \\
\hline Participants & $\begin{array}{l}117 \mathrm{k} \text { in total (visitors) } \\
\text { Except for a few thousand at outlying locations outside } \\
\text { of Tokyo, no fans were allowed throughout the OG. } \\
\text { Some PG sites allowed a few thousand schoolchildren } \\
\text { to attend. }\end{array}$ & $\begin{array}{l}1.7 \text { million nearly (visitors) anticipated }=58.6 \% \text { of the entire Qatar population } \\
\text { Competition has been divided into eight playing locations. } \\
\text { Stadiums average venue capacity: } 47500 \text { seats } \\
\text { The most distant venues are only } 55 \mathrm{~km} \text { apart. }\end{array}$ \\
\hline $\begin{array}{l}\text { Countries' demography (as per November } 2021 \\
\text { statistics) }\end{array}$ & $\begin{array}{l}\text { Population of Japan: } 125.8 \text { million } \\
\text { Japan population density: } 347 \mathrm{hab} / \mathrm{km}^{2} \\
\text { Tokyo (capital) population density: } 6158 \mathrm{hab} / \mathrm{km}^{2}\end{array}$ & $\begin{array}{l}\text { Population of Qatar: } 2.9 \text { million } \\
\text { Qatar population density: } 185 \text { hab } / \mathrm{km}^{2} \\
\text { Doha (capital) population density: } 6.037 \mathrm{hab} / \mathrm{km}^{2}\end{array}$ \\
\hline Countries' surface area $\left(\mathrm{km}^{2}\right)$ & 377975 & 11571 \\
\hline
\end{tabular}

Local vaccine coverage at the beginning of the OG $25 \%$ fully vaccinated (two doses)

(23 July 2021)

Local vaccine coverage up to date of manuscript $\quad 76.0 \%$ fully vaccinated (two doses) submission (November 2021)

Previous experience in holding big events during No

the COVID-19 pandemic

Duration of the whole event

Number of sporting disciplines

Eligible guests to participate in the event

29 days in total: 17 days for the $\mathrm{OG}$ and 12 for the PG 49 in $O G$ and 23 in PG

$70 \%-80 \%$ of the media representatives, as well as $85 \%$ of the residents at the Olympic Village had to be vaccinated.

Time to prepare for the event

There was much hesitancy regarding the likelihood of the Tokyo OG to happen

Despite long-term preparation (16 July 2011, Japan was announced as host of the 2020 Summer OG, 9 years in advance), the final decision was made just a year before to postpone from 2020 to 2021 .

Healthcare systems during the event

Good preparedness and no casualties have been reported especially as Japan succeeded to decrease the number of positive cases per million population from 183 corresponding to the number of positive cases at the closing ceremony of the PG (5 September 2021) to

1.18 (November 2021) after the surge of positive cases during the $O G$.

Infection control before boarding to the organiser Two negative RT-PCR test results in the 96 hours country leading up to arrival in Japan

Infection control on arrival

Tracking travellers

Daily infection control policies

Winning ceremony infection control

Olympic guests were administered a rapid antigen saliva test on arrival while being required to remain a the airport until the test result was negative.

All guests had to instal location-based contact tracing apps on their phones and restrict their movements within the country to 'designated bubbles'.

People in the designated areas were subjected to two coronavirus rapid antigen tests a day.

People were required to always wear face masks, except when sleeping, eating or competing.

Many winning ceremonies for the OG and PG (over 200)

Athletes who won gold, silver or bronze medals were

forced to place their medals around their necks on the podium.

Athletes who were done competing had to depart the country within 2 days of their final event

Security and tracking guest activities

Tokyo hotels were instructed to keep track of their guests' activities.

It has been reported that hotel personnel were subsequently frustrated by their involvement in maintaining the bubble around Olympic delegations.

Travelling back to own country, 'infection control'

RT-PCR negative test was required before boarding and going back to guests' respective countries to ensure that athletes and their supporting staff do not unintentionally bring a variation home. $49 \%$ fully vaccinated (two doses)

$85.1 \%$ fully vaccinated (two doses)

- 2020 Amir Football Cup: hosted $20 \mathrm{k}$ at the peak of the pandemic (December 2020).

- 2020 AFC (December 2020): 77 matches were successfully held throughout the event with some fans reported.

No vaccines were available during the period of the aforementioned two events.

Before the aforementioned two events, social distance, temperature screening and maskwearing were required before admission.

The antigen test and monitoring findings were recorded using a geolocating cell phone app and an online booking system. While this was a pricey experiment for both organisers and viewers (the spectator was responsible for any required tests), these events mitigated the danger of COVID-19.

- 2021 FIFA Arab Football Cup (November 2021): considered as a test for the FIFA WC-2022 For this event, less rigorous infection control policies were implemented, allowing fans to remove their masks inside the stadium as most of the fans were vaccinated.

A mandatory negative rapid antigen test or up-to-date vaccination was required to get into the stadium. Those data were recorded in a geolocating cell phone app called 'Ehteraz'.

28 days

Not divulged by the local authorities yet

For the AFC 2020 and for the FIFA Arab Football Cup 2021: a quarantine of 1 week was required for any unvaccinated incomer to Doha.

2 December 2010: Qatar was announced to host the FIFA WC 2022 (12 years in advance). Qatar has been studying infection control policies to deal with mass event organisation since COVID-19 was announced as a pandemic (will be $\sim 3$ years prior to the FIFA WC 2022 start date)

Qatar provides public health services mainly through the Primary Healthcare Corporation. The latter manages 28 health centres and is planning to adopt the FIFA WC mass-casualty incident plan in addition to other healthcare institutions such as Hamad Medical Corporation. The latter will be prepared for mass casualties and COVID-19 emergencies as needed.

Not divulged by the local authorities yet

A similar approach to Tokyo's policy has been implemented at the AFC 2020 and FIFA Arab Football Cup 2021.

Not divulged by the local authorities yet

A similar approach to Tokyo's policy has been implemented in AFC 2020 and in Arab Football Cup 2021.

Location-based contact tracing apps have been implemented in Qatar since the beginning of the pandemic and will be maintained for the FIFA WC2022.

Not divulged by the local authorities yet

Only one winning ceremony at the final day

Qatar has a dedicated police team for 'stadium security', which has been specifically trained over more than 4 years for this event.

Tracking of guests' activities is expected to be considered if needed.

Not divulged by the local authorities yet

A similar approach to Tokyo's policy has been implemented in the AFC 2020 and in FIFA Arab Football Cup 2021.

AFC, Asian Football Cup; OG, Olympic Games; PG, Paralympic Games; RT-PCR, reverse transcription PCR; WC, World Cup. 
Twitter Ismail Dergaa @IDergaa, Helmi Ben Saad @HHHMMBENSAAD and Karim Chamari @ProfChamari

Contributors Conceptualisation, review and editing: ID, KC and HBS; drafting, preparation and writing of the manuscript: ID, HBS, AS, SM, MAA and KC. All authors read and agreed to the published version of the manuscript.

Funding The authors have not declared a specific grant for this research from any funding agency in the public, commercial or not-for-profit sectors.

Competing interests None declared.

Patient consent for publication Not applicable.

Ethics approval This study does not involve human participants.

Provenance and peer review Not commissioned; externally peer reviewed.

(C) Author(s) (or their employer(s)) 2022. No commercial re-use. See rights and permissions. Published by BMJ.

D Check for updates
To cite Dergaa I, Ben Saad H, Souissi A, et al. Br I Sports Med Epub ahead of print: [please include Day Month Year]. doi:10.1136/bjsports-2021-105276

Accepted 16 February 2022

Br J Sports Med 2022:0:1-3. doi:10.1136/bjsports-2021-105276

\section{ORCID iDs}

Ismail Dergaa http://orcid.org/0000-0001-8091-1856 Helmi Ben Saad http://orcid.org/0000-0002-74772965

Amine Souissi http://orcid.org/0000-0003-2072-2425

Karim Chamari http://orcid.org/0000-0001-9178-7678

\section{REFERENCES}

1 Dergaa I, Abdelrahman H, Varma A, et al. COVID-19 vaccination, herd immunity and the transition toward normalcy: challenges with the upcoming sports events. Ann Appl Sport Sci 2021;9:e1032.

2 Shimizu K, Sridhar D, Taniguchi K, et al. Reconsider this summer's Olympic and Paralympic games. BMJ 2021;373:n962.

3 Sparrow AK, Brosseau LM, Harrison RJ, et al. Protecting Olympic participants from Covid-19-the urgent need for a risk-management approach. N Engl $\int$ Med 2021;385:e2.

4 Borpujari P. How the pandemic Olympics affected Japan. BMJ 2021;27:n2102.

5 Alshahrani NZ, Alhashim LA, Almohaishi HA. FIFA World cup 2022 in Qatar; health advice and safety issues for travelling Attendees. Ann Med Health Sci Res 2021:11:417-22.

6 Dergaa I, Musa S, Romdhani M. FIFA World cup 2022: what can we learn from the inspiring Tokyo 2020 Olympic Games experience held in COVID-19 times? Biol Sport 2022;39:1073-80.

7 Dergaa I, Varma A, Tabben M, et al. Organising football matches with spectators during the COVID-19 pandemic: what can we learn from the Amir cup football final of Qatar 2020? A call for action. Biol Sport 2021;38:677-81.

8 WHO. Update on omicron. Available: https://www. who.int/news/item/28-11-2021-update-on-omicron

9 Sherina N, Piralla A, Du L, et al. Persistence of SARSCoV-2-specific $B$ and $T$ cell responses in convalescent COVID-19 patients 6-8 months after the infection. Med 2021;2:281-95.

10 Di Meo A, Miller JJ, Fabros A. Evaluation of three antiSARS-CoV-2 serologic immunoassays for post-vaccine response. JALM 2021:jfab087. 